\title{
A midpoint perspective on the COVID-19 pandemic
}

\author{
Li Yang $\underline{\mathrm{Hs}}^{1,2}$, MBBS, MPH, Po Ying $\underline{C h i a}^{3}$, MBBS, MRCP, Shawn $\underline{V a s o o}^{3}$, MBBS, ABIM
}

\section{INTRODUCTION}

This report comes in the fourth month of the novel coronavirus SARS-CoV-2 (severe acute respiratory syndrome coronavirus 2) epidemic, which was notified to the World Health Organization (WHO) on 31 December 2019. (1) Beginning in Wuhan, China, in the final months of 2019, the virus has - as of 8 March 2020 spread to 100 territories in all continents outside mainland China, resulting in over 105,000 cases and 3,500 deaths, the majority of which have been in China. ${ }^{(2)}$

Although the epidemic in China peaked in February, other countries have started to see significant sustained community transmission, particularly South Korea, Italy and Iran. Italy and Iran have also served as secondary epicentres for the spread of SARS-CoV-2 to other countries in Europe and the Middle East, respectively. Singapore has not been spared, with 138 confirmed cases diagnosed between 23 January and 8 March 2020, with sustained if limited community transmission.

The WHO is still working with member states to contain the virus. ${ }^{(3)}$ However, it is increasingly clear that such efforts will not be successful and that a full-blown pandemic will occur. Nonetheless, such efforts, as well as those employed during the subsequent mitigation phase, will slow the spread of the virus through populations. This will provide time for countries to prepare, including for a potential second wave of the epidemic, as well as to prevent healthcare systems from being overwhelmed.

This epidemic has already contributed many important experiences and lessons both in the world and Singapore specifically, with doubtless more to come. We summarise some of the key points in this article.

\section{LESSONS FROM THE PANDEMIC Evaluate every novel virus and outbreak based on its own characteristics}

When a coalition of Chinese scientists announced that causative pathogen of the outbreak in Wuhan in early January 2020 was a novel coronavirus, ${ }^{(4)}$ many people - including one of the authors of this piece - believed that its behaviour would be similar to SARS-CoV or MERS-CoV (Middle East respiratory syndromerelated coronavirus) (Table I). Both of these zoonotic epidemic coronaviruses had high case fatality rates but spread relatively poorly between humans in the community setting. This seemed to fit with the earliest reports from Wuhan, where human transmission was limited, but the coronavirus disease 2019 (COVID-19) was severe in a large proportion of diagnosed cases. ${ }^{(5)}$

As more data became available, however, it became clear that SARS-CoV-2 was as effective as the human influenza viruses at spreading in the community. Its infection fatality rate is currently estimated at $0.3 \%-1.0 \%,{ }^{(6)}$ far lower than SARS or MERS but certainly far higher than seasonal influenza. Perhaps only the 1918 pandemic influenza virus came closest in terms of transmissibility and virulence (Table I). ${ }^{(6-12)}$

Comparisons were also made between the SARS-CoV-2 outbreak and seasonal influenza, with the primary argument being that seasonal influenza resulted in more deaths. ${ }^{(10)}$ These comparisons seemed disingenuous, given that they were made during the initial phase of the SARS-CoV-2 outbreak and that efforts to stop the spread of seasonal influenza came nowhere near the scale of current efforts to contain SARS-CoV-2. In 2009, after ascertaining that influenza $\mathrm{A}(\mathrm{H} 1 \mathrm{~N} 1)$ pdm09 was no more virulent than seasonal influenza, many countries including Singapore went rapidly into mitigation mode rather than attempting to contain the virus.

\section{Great advancements in speed and power of science and international collaboration}

The rapid pace at which scientific results are gleaned and shared globally, particularly by the Chinese, is truly amazing, especially relative to events during the SARS epidemic in 2003. Within two weeks of understanding that they had an unusual outbreak in Wuhan, Chinese scientists and clinicians had isolated and cultured the virus, sequenced its genome, and provided a blueprint for the development of reverse transcription-polymerase chain reaction testing that the $\mathrm{WHO}$ helped to disseminate. ${ }^{(1,4)}$ Modelling projections on the scale of the outbreak in China as well as estimations of the transmissibility and infection fatality rate of SARS-CoV-2 were published by early February $2020,{ }^{(8,13)}$ with more in the pipeline, while numerous case series with clinical and epidemiological data were published by both Chinese and international clinicians and epidemiologists. ${ }^{(5,14)}$ Multiple clinical trials in therapeutics and vaccines are ongoing, and results are eagerly awaited.

In the rapid dissemination of scientific information, key roles were played by the preprint servers, especially medRxiv (https:// www.medrxiv.org) and the top medical journals, each of which maintained COVID-19 webpages that made available accepted scientific papers that had undergone rapid peer review. There are also a number of key open access repositories, including one set up by the Open COVID-19 Data Curation Group that has a line listing of available de-identified cases with epidemiological information, ${ }^{(15)}$ while phylogenetic analysis on publicly available viral genomes (including eight contributed by Singapore) is being performed at open source project Nextstrain. ${ }^{(16)}$ 
Table I. A comparison between epidemic coronaviruses and seasonal/pandemic influenza viruses.

\begin{tabular}{|lllll|}
\hline Virus & Ro & Infection fatality rate & Estimated mortality & Reference \\
\hline SARS-CoV-2 & $2.0-2.5$ & $0.3 \%-1.0 \%$ & Unknown & 6,7 \\
\hline SARS-CoV & $0.7-1.2$ & $9.6 \%$ & 774 in 2003 & 8 \\
\hline MERS-CoV & $0.4-1.4$ & $34.4 \%$ & 858 in 2012-2019 & 8 \\
\hline Seasonal influenza & $0.9-2.1$ & $0.004 \%-0.008 \%$ & $291,243-645,832$ per year & 9,10 \\
\hline Influenza A(H1N1)pdm09 & $1.4-1.6$ & $<0.1 \%$ & $151,700-575,500$ in 2009 & 9,11 \\
\hline 1918 pandemic influenza A & $1.4-2.8$ & $>1.0 \%$ & 50 million & 9,12 \\
\hline
\end{tabular}

R0: basic reproduction number; MERS-CoV: Middle East respiratory syndrome-related coronavirus; SARS-CoV: severe acute respiratory syndrome coronavirus

\section{Public risk communication and contesting 'misinfodemics' are critical in outbreaks}

Timely and transparent sharing of information, particularly if the news is adverse, and projecting uncertainty explicitly are an integral part of the management of large-scale epidemics and other emergencies. ${ }^{(17)}$ Such communication should be routine practice between government agencies and the public in order to build trust, which becomes crucial during epidemics. In today's world, reaching the public - particularly during a crisis - requires more than the mainstream media, some of which are behind paywalls. Social media channels are necessary to rapidly reach a larger proportion of the population and obtain feedback about the handling of the crisis as well as to find out about the specific concerns of different segments of the population. ${ }^{(17)}$

Much has been said about how the local Wuhan authorities' attempts at secrecy and delaying the release of critical information - including knowledge that the virus was able to spread between humans - resulted in the tragedy of Wuhan and the spread of the virus through China and to the rest of the world. ${ }^{(18)}$ Subsequent public communication from China and its sharing of information improved along with the outbreak response, which led to the outbreak peaking and coming under control in the country since February. Meanwhile, Singapore's approach to public risk communication, including the speech by Prime Minister Lee Hsien Loong on 8 February 2020, has been praised by experts as a model for reducing panic and rumours. ${ }^{(19)}$

Of equal importance with timely and transparent sharing of information is the effort to combat 'misinfodemics' about the virus. ${ }^{(20)}$ There has been an epidemic of misinformation online and on social media about 'cures' for the virus and that it was a biological weapon engineered in the Wuhan Institute of Virology. The Singapore government has taken an active stance against the dissemination of misinformation regarding the outbreak, publishing clarifications on its website to major circulating rumours and even invoking its fake news law (Protection from Online Falsehoods and Manipulation Act) against false claims on the coronavirus. ${ }^{(21)}$

\section{Outbreak control and mitigation goes beyond the healthcare sector}

Perhaps more clearly than any other outbreak in recent times, the SARS-CoV-2 has highlighted the importance of a whole-of-society approach to preparing and dealing with such events. Health system resilience, including the ability to adapt, absorb and transform in response to different stages of the epidemic, is certainly critical. ${ }^{(22)}$ Hospitals can be quickly overwhelmed by a high number of cases presenting over a short period of time, as happened in Wuhan, China ${ }^{(7,14)}$ and Daegu, South Korea, ${ }^{(23)}$ and efficient case detection and contact tracing is important to flatten the epidemic curve. Nonetheless, maintaining public trust by, for example, reducing panicked stockpiling, and therefore avoiding a subsequent tragedy of the commons, is equally important, along with supporting sectors of the economy that are hardest hit, such as aviation and tourism. ${ }^{(24)}$

\section{CONCLUSION}

The SARS-CoV-2 epidemic presents a global dilemma not seen since the 1918 influenza pandemic. Relative to prior pandemics, we now have far greater capabilities and resources to contain the virus, but also far greater vulnerabilities in a highly interlinked world and economy. The virus currently appears too efficiently transmitted to be stopped but also too lethal to be ignored. Several countries including Singapore have effectively flattened the epidemic curve, but SARS-CoV-2 has reached territories where societal and health systems are less able to contain its spread and, as such, the threat of recurrent importation and a 'second wave' will likely be present for the next several months at least. Prolonged escalation will stress healthcare workers and at some point compromise clinical care, not just for COVID-19 patients but also for those with other medical conditions. The many lessons learnt will serve as a blueprint for dealing with future pandemics, although a sustainable new normal is required for the immediate future.

\section{REFERENCES}

1. World Health Organization. Novel coronavirus (2019-nCoV) situation report - 1. 21 January 2020. Available at: https://www.who.int/docs/default-source/ coronaviruse/situation-reports/20200121-sitrep-1-2019-ncov.pdf. Accessed March 8, 2020

2. Worldometer. COVID-19 coronavirus outbreak. 8 March 2020. Available at: https://www.worldometers.info/coronavirus/\#countries. Accessed March 8, 2020.

3. World Health Organization. WHO Director-General's opening remarks at the media briefing on COVID-19 - 5 March 2020. Available at: https://www.who. $\mathrm{int} / \mathrm{dg} / \mathrm{speeches/detail/who-director-general-s-opening-remarks-at-themedia-}$ briefing-on-covid-19---5-march-2020. Accessed March 8, 2020.

4. Lu R, Zhao X, Li J, et al. Genomic characterisation and epidemiology of 2019 novel coronavirus: implications for virus origins and receptor binding. Lancet 2020; 395:565-74.

5. Huang C, Wang Y, Li X, et al. Clinical features of patients infected with 2019 novel coronavirus in Wuhan, China. Lancet 2020; 395:497-506.

6. World Health Organization. Coronavirus disease 2019 (COVID-19). Situation report - 30. 19 February 2020. Available at: https://www.who.int/docs/ 
defaultsource/coronaviruse/situation-reports/20200219-sitrep-30-covid-19 pdf?sfvrsn=3346b04f_2. Accessed March 8, 2020.

7. World Health Organization. Report of the WHO-China Joint Mission on Coronavirus Disease 2019 (COVID-19). 16-24 February 2020. Available at: https://www.who.int/docs/default-source/coronaviruse/who-china-jointmission-oncovid-19-final-report.pdf. Accessed March 2, 2020.

8. Wu JT, Leung K, Leung GM. Nowcasting and forecasting the potential domestic and international spread of the 2019-nCoV outbreak originating in Wuhan China: a modelling study. Lancet 2020; 395:689-97.

9. Coburn BJ, Wagner BG, Blower S. Modeling influenza epidemics and pandemics: insights into the future of swine flu (H1N1). BMC Med 2009; 7:30

10. Iuliano AD, Roguski KM, Chang $\mathrm{HH}$, et al. Estimates of global seasonal influenzaassociated respiratory mortality: a modelling study. Lancet 2018; 391:1285-300.

11. Dawood FS, luliano AD, Reed C, et al. Estimated global mortality associated with the first 12 months of 2009 pandemic influenza A H1N1 virus circulation: a modelling study. Lancet Infect Dis 2012; 12:687-95.

12. Taubenberger JK, Morens DM. The 1918 influenza pandemic and its legacy. Cold Spring Harb Perspect Med 2019 Dec 30. doi: 10.1101/cshperspect.a038695. [Epub ahead of print]

13. Imperial College London. COVID-19 reports. Available at: https://www.imperial. ac.uk/mrc-global-infectious-disease-analysis/news--wuhancoronavirus/. Accessed March 8, 2020.

14. Wu Z, McGoogan JM. Characteristics of and important lessons from the coronavirus disease 2019 (COVID-19) outbreak in China: summary of a report of 72,314 cases from the Chinese Center for Disease Control and Prevention. JAMA 2020; 323:1239-42.

15. Open COVID-19 Data Curation Group. COVID19_2020_open line_list. Available at: https://docs.google.com/spreadsheets/d/1 itaohdPiAeniCXNIntNztZ_ oRvjhOHsGuJXUJW ET008/edit\#gid=0. Accessed March 8, 2020
16. Nextstrain. Genomic epidemiology of novel coronavirus (hCoV-19). Available at: https://nextstrain.org/ncov. Accessed March 8, 2020.

17. World Health Organization. Communicating riskin publichealthemergencies. AWHO guideline for emergency risk communication (ERC) policy and practice. Available at: https://apps.who.int/iris/bit stream/handle/10665/259807/9789241550208eng. pdf; jsessionid $=$ D6796FA0ECAD7D6A4E4C5456A762BDB2 ? sequence $=2$. Accessed March 8, 2020.

18. Zhang H. Early lessons from the frontline of the 2019-nCoV outbreak. Lancet 2020; 395:687.

19. Heijman P, Gale J. As Asia panics, one country wins praise for approach to virus. In: Bloomberg [online]. 10 February 2020. Available at: https://www.bloomberg. com/news/articles/2020-02-10/as-asia-panics-one-country-winspraise-forapproach-to-virus. Accessed March 8, 2020.

20. Gold H. Inside the WHO's fight to stop false information about coronavirus from spreading. In: CNN Business [online]. 5 March 2020. Available at: https://edition. cnn.com/2020/03/05/tech/facebook-google-who-coronavirusmisinformation/ index.html. Accessed March 8, 2020

21. Tham YC. Coronavirus: Govt invokes fake news law against false claims by States Times Review. In: The Straits Times [online]. Available at: https://www. straitstimes.com/politics/coronavirus-govt-invokes-fake-news-law-againstfalseclaims-by-states-times-review. Accessed March 8, 2020.

22. Legido-Quigley H, Asgari N, Teo YY, et al. Are high performing health systems resilient against the COVID-19 epidemic? Lancet 2020; 395:848-50.

23. Yonhap News Agency. S. Korea struggles to acquire hospital beds amid spike in new coronavirus cases. Available at: https://en.yna.co.kr/view/ AEN20200228001951320. Accessed March 8, 2020.

24. Peckham R. The COVID-19 outbreak has shown we need strategies to manage panic during epidemics. 2020. In: The BMJ Opinion [online]. Available at: https://blogs.bmj.com/bmj/2020/02/21/robert-peckham-covid-19-outbreakneedstrategies-manage-panic-epidemics. Accessed March 8, 2020. 